\title{
Tolerability and safety of novel half milliliter formulation of glatiramer acetate for subcutaneous injection: an open-label, multicenter, randomized comparative study
}

\author{
G. Anderson - D. Meyer - C. E. Herrman • \\ C. Sheppard $\cdot$ R. Murray $\cdot$ E. J. Fox • \\ J. Mathena $\cdot$ J. Conner $\cdot$ P. O. Buck
}

Received: 18 May 2010/Revised: 17 August 2010/Accepted: 29 September 2010/Published online: 16 October 2010

(C) The Author(s) 2010. This article is published with open access at Springerlink.com

\begin{abstract}
Daily glatiramer acetate (GA) $20 \mathrm{mg} / 1.0 \mathrm{~mL}$ is a first-line treatment for relapsing-remitting multiple sclerosis (RRMS). To reduce the occurrence of injection pain and local injection site reactions (LISRs), a reduced volume formulation of GA was developed. This study compared pain and LISRs after injecting the marketed and the novel formulations. RRMS patients currently injecting GA participated in this multicenter, randomized, crossover comparative study. All patients administered once-daily subcutaneous injections of GA $20 \mathrm{mg} / 1.0 \mathrm{~mL}$ (marketed
\end{abstract}

Electronic supplementary material The online version of this article (doi:10.1007/s00415-010-5779-x) contains supplementary material, which is available to authorized users.

\section{G. Anderson ( $\square)$}

Associates in Neurology PSC, 1021 Majestic Dr. Suite \#200, Lexington, KY 40513, USA

e-mail: Greg.l.anderson@insightbb.com

D. Meyer

Triad Neurological Associates, Winston-Salem, NC, USA

C. E. Herrman

Josephson Wallack Munshower Neurology PC,

Indianapolis, IN, USA

C. Sheppard

The Oak Clinic for MS, Uniontown, OH, USA

R. Murray

MS Clinic of Colorado, 1st International Research Centers, Centennial, CO, USA

E. J. Fox

Central Texas Neurology Consultants,

Round Rock, TX, USA

J. Mathena $\cdot$ J. Conner $\cdot$ P. O. Buck

Medical Affairs, Teva Neuroscience, Kansas City, MO, USA formulation) or GA $20 \mathrm{mg} / 0.5 \mathrm{~mL}$ (reduced volume formulation) for 14 days. Patients were crossed-over to the alternate treatment for an additional 14 days. Using a Visual Analog Scale (VAS), patients recorded in daily diaries the severity of injection pain immediately and $5 \mathrm{~min}$ post-injection, and the presence and severity of LISRs (swelling, redness, itching, lump) within $5 \mathrm{~min}$ and $24 \mathrm{~h}$ post-injection. VAS pain scores were ranked significantly lower immediately and $5 \mathrm{~min}$ after GA $20 \mathrm{mg} / 0.5 \mathrm{~mL}$ injections $(p<0.0001)$. Although LISRs were rare for both preparations, the severity of reactions ranked significantly lower and fewer symptoms occurred within $5 \mathrm{~min}$ and $24 \mathrm{~h}$ of using the reduced volume formulation $(p<0.0001)$. GA injected subcutaneously in a reduced volume formulation is a more tolerable option.

Keywords Relapsing-remitting multiple sclerosis . Glatiramer acetate - Copaxone - Subcutaneous injections · Local injection site reactions - Injection pain

\section{Introduction}

Glatiramer acetate (GA) injection (Copaxone, Teva Pharmaceuticals Inc., Petah Tiqva, Israel) is indicated for reducing the frequency of relapses in patients with relapsing-remitting multiple sclerosis (RRMS), and in patients who have experienced a first clinical episode and have MRI features consistent with multiple sclerosis (MS) [1]. This first-line treatment has proven efficacy and safety [2-6]. As with all therapeutics, patient adherence to the treatment regimen is very important. Patients with chronic diseases have lower drug adherence and persistence rates [7], with studies of MS patients reporting that almost $40 \%$ of patients with MS miss injections [8-10]. Many factors can lead to 
poor adherence with any medication [7]; patients have reported that local injection site reactions (LISRs) and injection site pain are a couple of the reasons why they miss injections [10, 11].

LISRs, including pain, are the most common adverse reactions reported by patients receiving GA [1]. In controlled studies, the proportion of subjects reporting these reactions at least once was higher following treatment with GA than following placebo [2, 4, 5]. Although the etiology of injection site pain is multi-factorial, an increase in the volume of an injectable agent has been associated with increased injection site pain [12]. A study assessing four volumes of a subcutaneous injection found that increasing the volume from 0.5 to $1.0 \mathrm{~mL}$ increased injection pain significantly [12]. In an attempt to potentially reduce the occurrence of injection pain and other injection site reactions, a reduced volume of the GA formulation was developed. The new formulation contains $20 \mathrm{mg}$ GA and $20 \mathrm{mg}$ mannitol in $0.5 \mathrm{~mL}$ whereas the marketed formulation contains $20 \mathrm{mg}$ GA and $40 \mathrm{mg}$ mannitol in $1.0 \mathrm{~mL}$ solution. The objective of this study was to assess injection pain and other LISRs associated with the reduced volume formulation by comparing it to the marketed formulation.

\section{Methods}

\section{Study design}

The study was a multicenter, randomized, two-arm, single crossover study designed to compare the tolerability and safety of GA $20 \mathrm{mg} / 0.5 \mathrm{~mL}$ versus GA $20 \mathrm{mg} / 1.0 \mathrm{~mL}$ when administered subcutaneously by patients with RRMS. During the 7-day run-in period preceding the two treatment periods, all patients administered a daily subcutaneous dose of GA $20 \mathrm{mg} / 1.0 \mathrm{~mL}$. During this period they were instructed on a 7-site injection rotation, manual injection techniques, and how to complete the patient diary. They were also randomized at a ratio of 1:1 to one of two crossover sequences of either GA $20 \mathrm{mg} / 1.0 \mathrm{~mL}$ or GA $20 \mathrm{mg} /$ $0.5 \mathrm{~mL}$ (Sequences 1 and 2) for the two treatment periods. During the treatment periods, patients administered one of the formulations of GA for 14 days and then the patients were crossed-over to the alternate formulation for an additional 14-day treatment period. Total GA treatment duration in the study was 5 weeks, including the 1 -week run-in period. Block randomization stratified by study site was done according to a computer-generated schedule to ensure that patients of each site were distributed equally between the formulation sequences. Blinding in this study was not possible due to the patients' ability to detect difference in the volumes of each formulation. The study was conducted following the principles of the Declaration of Helsinki, ICH guidelines on good clinical practices, and all applicable laws and regulations. All patients gave written informed consent after the procedures had been fully explained, and prior to performing any study related procedures.

\section{Patients}

Men or women, aged $\geq 18$ years, with a diagnosis of RRMS and taking GA $20 \mathrm{mg} / 1.0 \mathrm{~mL}$ per day subcutaneously with the Autoject ${ }^{\circledR} 2$ for glass syringe or by a manual injection technique for a minimum of 90 days were eligible for inclusion. They also had to be willing to switch from using an Autoject ${ }^{\circledR} 2$ for glass syringe to using a manual injection technique or to continue with a manual injection technique during the course of the study. Patients were excluded if in the 30 days prior to screening (1) they were treated with another immunomodulating therapy in conjunction with $\mathrm{GA}$, (2) they used intermittent or pulse courses of corticosteroids by any route of administration (corticosteroids were prohibited for the duration of the study), or (3) used any other parenteral medications. Patients with a presence or history of skin necrosis or a known extensive dermatological condition were excluded to prevent a potential confounding factor in the assessment of LISRs.

\section{Treatments}

During the 7-day run-in period preceding the two treatment periods, all patients administered a daily subcutaneous dose of GA $20 \mathrm{mg} / 1.0 \mathrm{~mL}$. After the run-in period all patients received once-daily subcutaneous administration of $20 \mathrm{mg}$ $\mathrm{GA}$, as either $20 \mathrm{mg} / 1.0 \mathrm{~mL}$ or $20 \mathrm{mg} / 0.5 \mathrm{~mL}$, for a 14-day treatment period, and then received the second (alternate) treatment as per the randomization schedule for an additional 14-day treatment period. Both the $20 \mathrm{mg} / 1.0 \mathrm{~mL}$ and $20 \mathrm{mg} / 0.5 \mathrm{~mL}$ formulations of GA have a $\mathrm{pH}$ range of approximately 5.5-7.0 and are stable for up to 1 month at room temperature with no adverse impact on product potency, appearance, $\mathrm{pH}$, clarity or other physicochemical characteristics. All treatments were administered via a manual injection technique. Compliance with the dosing regimen for each period was determined by counting returned unused study drug syringes.

\section{Outcome measures}

Using daily diaries, patients recorded the severity of pain occurring immediately and $5 \mathrm{~min}$ after injection, and the presence and severity of LISRs that occurred within $5 \mathrm{~min}$ and $24 \mathrm{~h}$ post-injection. Daily diaries were collected at the end of the run-in period, at the end of Treatment Period 1 (before they were crossed-over to Period 2), and at the end of Treatment Period 2. 
The primary clinical outcome was the difference between the two GA formulations in the total injection pain rating occurring immediately after injection as reported on a Visual Analog Scale (VAS). Daily injection pain was rated by the patients with a $100 \mathrm{~mm}$ VAS, where $0 \mathrm{~mm}$ represented "no pain" and $100 \mathrm{~mm}$ represented "worst possible pain." Injection pain occurring $5 \mathrm{~min}$ after the injection was also recorded daily on a $100 \mathrm{~mm}$ VAS (secondary outcome variable). Patients reported the presence or absence of LISRs and the degree of LISR severity that occurred within the $5 \mathrm{~min}$ and $24 \mathrm{~h}$ periods following the injection. LISR total presence scores could range from 0 to 4 for an individual patient depending on how many of the following symptoms were experienced: redness, itching, swelling, and lump. LISR total severity scores could range from 0 to 12 for an individual patient depending on the severity (rated $0-3$, with $0=$ none to $3=$ severe) of each of the following symptoms experienced: redness, itching, swelling, and lump.

\section{Safety measures}

Safety was monitored at each study site by assessing adverse events (AEs), evaluating laboratory values (hematology, chemistry, and urinalysis), conducting general physical examinations, and conducting nervous system examinations (including mental status, pupil and fundi, cranial nerves, motor examination, gait, coordination, reflexes, and sensory function).

\section{Statistical analysis}

The sample size (60 patients per group) was estimated to provide $80 \%$ power of detecting an effect of size $18 \%$ with a two-tailed $t$ test for correlated sample means with an alpha value of 0.05 . Four trained individuals at a central location measured the VAS ratings for all study patients and calculated the patient daily scores (inter-rater consistency was confirmed). Daily scores within each period were averaged to provide total pain ratings for each patient. Also daily scores within each period for LISRs were averaged to provide total LISR ratings.

All statistical analyses were performed using $\mathrm{SAS}^{\circledR}$ (SAS Institute Inc., Cary, NC), Version 8. The normality assumption was checked using data plots and the ShapiroWilk test for the primary clinical outcomes variable. Due to the non-normality of the data, ANOVA with mean ranked average scores and least square means (LS means) were used to compare the treatment outcomes. The ANOVA model for a two-treatment crossover study was run with treatment, sequence, and period as fixed effects, and patient within sequence as a random effect. The corresponding $95 \%$ confidence interval for treatment difference was calculated. Descriptive statistics for continuous variables consisted of $n$, mean, median, standard deviation (SD), standard error of the mean (SEM), minimum, and maximum values. Statistical significance was declared when $p<0.05$.

\section{Results}

Patient characteristics

The study was conducted from July 2009 to September 2009. Patients were recruited from 21 centers in the United States. A total of 148 patients were randomly assigned to Sequence 1 ( $n=76$, Period 1: GA $20 \mathrm{mg} / 1.0 \mathrm{~mL}$, Period 2: GA $20 \mathrm{mg} / 0.5 \mathrm{~mL})$ or Sequence $2(n=72$, Period 1: GA $20 \mathrm{mg} / 0.5 \mathrm{~mL}$, Period 2: GA $20 \mathrm{mg} / 1.0 \mathrm{~mL}$ ). Nearly all $(95.9 \%, 142 / 148)$ of the patients completed the study. Of the six patients who discontinued from the study, five patients withdrew consent and one did not meet the inclusion criteria but was mistakenly randomized. The majority of patients $(81.0 \%)$ were women, $90.5 \%$ of the population was Caucasian, and the mean age was 46.0 years (Table 1). The groups receiving Sequence 1 and Sequence 2 were comparable in demographic characteristics. Overall, $99.5 \%$ of patients were compliant in the administration of $20 \mathrm{mg} / 0.5 \mathrm{~mL} \mathrm{GA}$ and $99.6 \%$ of patients were compliant when administering the $20 \mathrm{mg} / 1.0 \mathrm{~mL}$ GA during the study.

Table 1 Patient demographics

\begin{tabular}{|c|c|c|c|}
\hline & $\begin{array}{l}\text { Sequence } 1^{\mathrm{a}} \\
(n=76)\end{array}$ & $\begin{array}{l}\text { Sequence } 2^{\mathrm{b}} \\
(n=71)\end{array}$ & $\begin{array}{l}\text { Total } \\
(N=147)\end{array}$ \\
\hline \multicolumn{4}{|l|}{ Age (years) } \\
\hline Mean \pm SD & $45.1 \pm 10.64$ & $46.9 \pm 9.64$ & $46.0 \pm 10.17$ \\
\hline Median & 45.0 & 48.0 & 47.0 \\
\hline Range & $24-71$ & $22-63$ & $22-71$ \\
\hline \multicolumn{4}{|l|}{ Gender, $n(\%)$} \\
\hline Male & $15(19.7)$ & $13(18.3)$ & $28(19.0)$ \\
\hline Female & $61(80.3)$ & $58(81.7)$ & $119(81.0)$ \\
\hline \multicolumn{4}{|l|}{ Race, $n(\%)$} \\
\hline Asian & $0(0.0)$ & $1(1.4)$ & $1(0.7)$ \\
\hline $\begin{array}{c}\text { Black or African } \\
\text { American }\end{array}$ & $2(2.6)$ & $4(5.6)$ & $6(4.1)$ \\
\hline Caucasian & $71(93.4)$ & $62(87.3)$ & $133(90.5)$ \\
\hline Other & $3(3.9)$ & $4(5.6)$ & $7(4.8)$ \\
\hline \multicolumn{4}{|c|}{$S D$ Standard deviation } \\
\hline
\end{tabular}


Primary outcome

The mean immediate VAS total pain score was $8.64 \mathrm{~mm}$ after administration of $20 \mathrm{mg} / 0.5 \mathrm{~mL} \mathrm{GA}$ and $11.89 \mathrm{~mm}$ after administration of $20 \mathrm{mg} / 1.0 \mathrm{~mL} \mathrm{GA} \mathrm{(Fig.} \mathrm{1).} \mathrm{Because}$ of the non-normal distribution of the VAS scores, the rank scores, rather than observed scores, were statistically compared. LS mean ranked immediate VAS scores were significantly lower after administration of $20 \mathrm{mg} / 0.5 \mathrm{~mL}$ GA than after $20 \mathrm{mg} / 1.0 \mathrm{~mL}$ GA $(p<0.0001$; LS mean 133.6, 95\% CI 120.0-147.2; and LS mean 154.7, 95\% CI 141.0-168.3; respectively). There were no significant effects associated with the treatment period or sequence of formulation. Throughout the 14-day treatment period, the

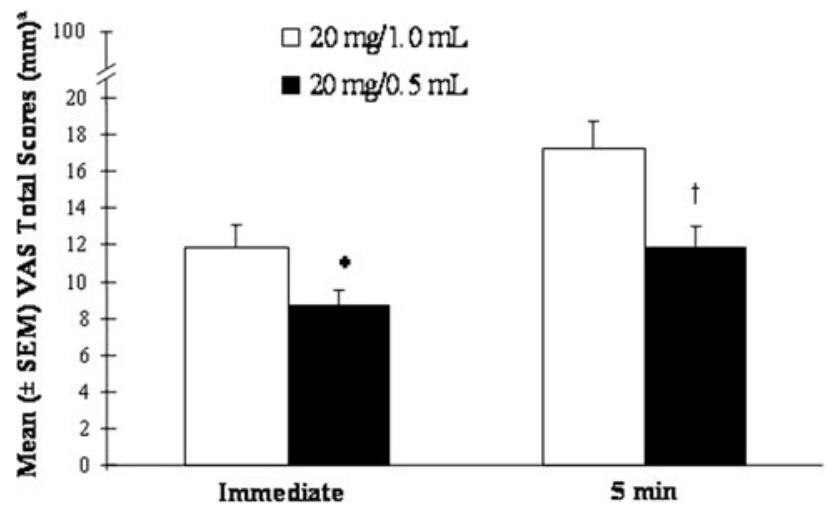

Fig. 1 VAS total pain scores (mean + SEM) recorded immediately and $5 \mathrm{~min}$ after injection of $20 \mathrm{mg} / 0.5 \mathrm{~mL} \mathrm{GA}$ or $20 \mathrm{mg} / 1.0 \mathrm{~mL} \mathrm{GA}$. aAs indicated on the $Y$ axis, the rating scale for VAS total pain scores was 0 "no pain" to $100 \mathrm{~mm}$ "worst possible pain." *p $<0.0001$; $20 \mathrm{mg} / 0.5 \mathrm{~mL}$ LS mean $133.6 \mathrm{~mm}, 95 \%$ CI 120.0-147.2; and $20 \mathrm{mg} /$ $1.0 \mathrm{~mL}$ LS mean $154.7 \mathrm{~mm}, 95 \%$ CI $141.0-168.3 .{ }^{\dagger} p<0.0001$; $20 \mathrm{mg} / 0.5 \mathrm{~mL}$ LS mean $130.4 \mathrm{~mm}, 95 \%$ CI $116.9-143.9$; and $20 \mathrm{mg} /$ $1.0 \mathrm{~mL}$ LS mean $157.6 \mathrm{~mm}, 95 \%$ CI $144.1-171.2$

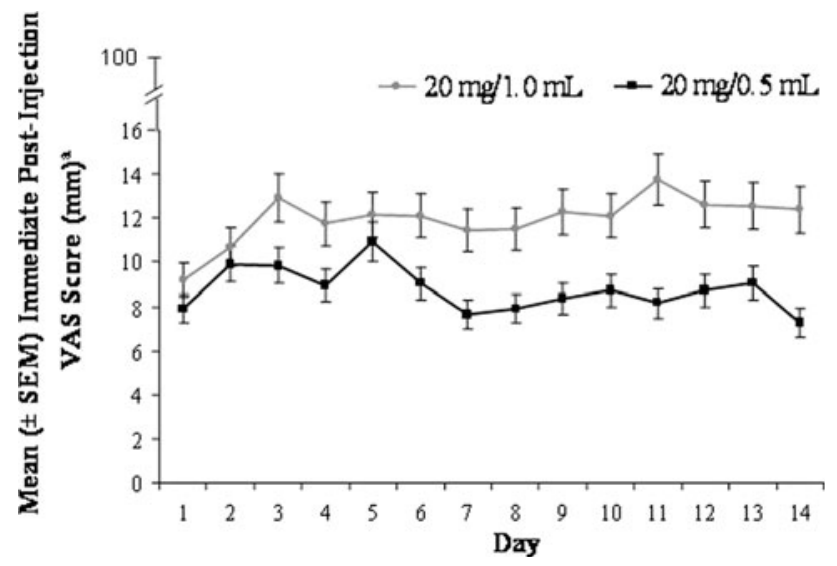

Fig. 2 Daily mean $( \pm$ SEM) immediate pain scores after injection of $20 \mathrm{mg} / 0.5 \mathrm{~mL}$ GA or $20 \mathrm{mg} / 1.0 \mathrm{~mL} \mathrm{GA}$. ${ }^{\mathrm{a}}$ As indicated on the $Y$ axis, the rating scale for VAS total pain scores was 0 "no pain" to $100 \mathrm{~mm}$ "worst possible pain." daily mean immediate pain score was consistently lower when the $20 \mathrm{mg} / 0.5 \mathrm{~mL}$ GA preparation was used than when the $20 \mathrm{mg} / 1.0 \mathrm{~mL}$ GA preparation was used (Fig. 2).

Secondary outcomes

VAS pain score

As illustrated in Fig. 1, mean VAS total pain scores 5 min after administration were $11.85 \mathrm{~mm}$ after the $20 \mathrm{mg}$ / $0.5 \mathrm{~mL}$ GA preparation and $17.19 \mathrm{~mm}$ after the $20 \mathrm{mg}$ / $1.0 \mathrm{~mL}$ GA preparation. The $20 \mathrm{mg} / 0.5 \mathrm{~mL}$ GA preparation was associated with significantly less pain 5 min postinjection than with the $20 \mathrm{mg} / 1.0 \mathrm{~mL}$ GA preparation; the mean ranked VAS scores differed by 27.2 ( $p<0.0001$; LS mean 130.4, 95\% CI 116.9-143.9; and LS mean 157.6, 95\% CI 144.1-171.2; respectively). There were no significant effects associated with the treatment period or sequence of formulation.

\section{Presence of LISRs}

When treated with $20 \mathrm{mg} / 0.5 \mathrm{~mL}$ GA the mean occurrence (presence) of LISRs within 5 min post-injection was 1.41 symptoms (maximum four symptoms), whereas when treated with $20 \mathrm{mg} / 1.0 \mathrm{~mL}$ GA the mean occurrence within 5 min post-injection was 1.85 symptoms (Fig. 3). As indicated by the LS mean analysis for treatment effect, the $20 \mathrm{mg} / 0.5 \mathrm{~mL}$ GA preparation produced significantly fewer LISRs within 5 min post-injection than the $20 \mathrm{mg}$ / $1.0 \mathrm{~mL}$ GA preparation $(p<0.0001$; mean ranked average $5 \mathrm{~min}$ LISR scores were 126.2 for the $20 \mathrm{mg} / 0.5 \mathrm{~mL} \mathrm{GA}$,

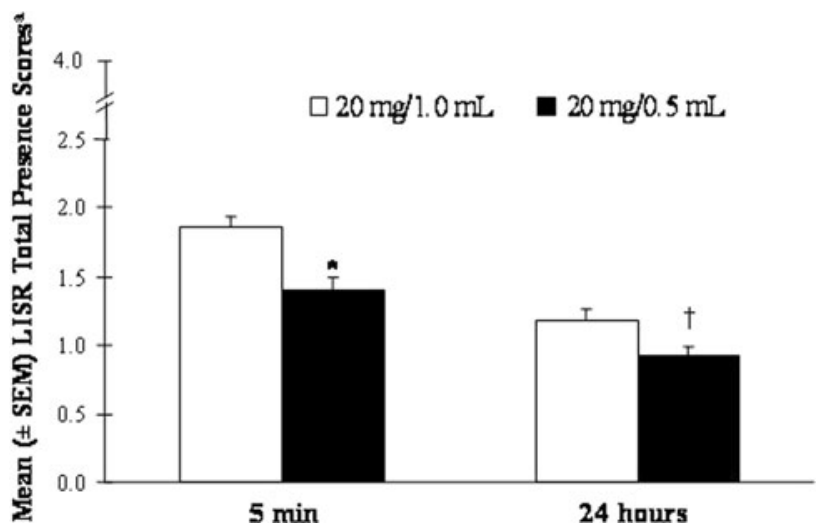

Fig. 3 Mean $( \pm$ SEM) occurrence of LISRs $5 \mathrm{~min}$ and $24 \mathrm{~h}$ after injection of $20 \mathrm{mg} / 0.5 \mathrm{~mL}$ GA or $20 \mathrm{mg} / 1.0 \mathrm{~mL}$ GA. ${ }^{\mathrm{a}} \mathrm{As}$ indicated on the $Y$ axis, the presence of symptoms scores could range from 0 "no symptoms" to 4 "all four symptoms occurred." * $p<0.0001$; $20 \mathrm{mg} / 0.5 \mathrm{~mL}$ LS mean 126.2 symptoms, 95\% CI 112.9-139.6; and $20 \mathrm{mg} / 1.0 \mathrm{~mL}$ LS mean 161.3 symptoms, 95\% CI 147.9-174.7. ${ }^{\dagger} p<0.0001 ; 20 \mathrm{mg} / 0.5 \mathrm{~mL}$ LS mean 132.0 symptoms, 95\% CI 118.5-145.6; and $20 \mathrm{mg} / 1.0 \mathrm{~mL}$ LS mean 155.8 symptoms, 95\% CI $142.2-169.3$ 
95\% CI 112.9-139.6 and 161.3 for the $20 \mathrm{mg} / 1.0 \mathrm{~mL} \mathrm{GA}$, 95\% CI 147.9-174.7). Neither treatment period nor preparation sequence affected the findings.

Within the 24-h time period, treatment with $20 \mathrm{mg}$ / $0.5 \mathrm{~mL}$ GA was associated with a mean presence of 0.92 LISR symptoms, whereas treatment with $20 \mathrm{mg} / 1.0 \mathrm{~mL}$ GA was associated with a mean presence of 1.19 LISR symptoms (Fig. 3). As indicated by the LS mean for treatment effect, the $20 \mathrm{mg} / 0.5 \mathrm{~mL}$ GA preparation produced significantly fewer LISRs within $24 \mathrm{~h}$ post-injection than the $20 \mathrm{mg} / 1.0 \mathrm{~mL}$ GA preparation $(p<0.0001$; mean ranked scores were 132.0, 95\% CI 118.5-145.6, and 155.8, 95\% CI 142.2-169.3, respectively, no effects of treatment period and formulation sequence).

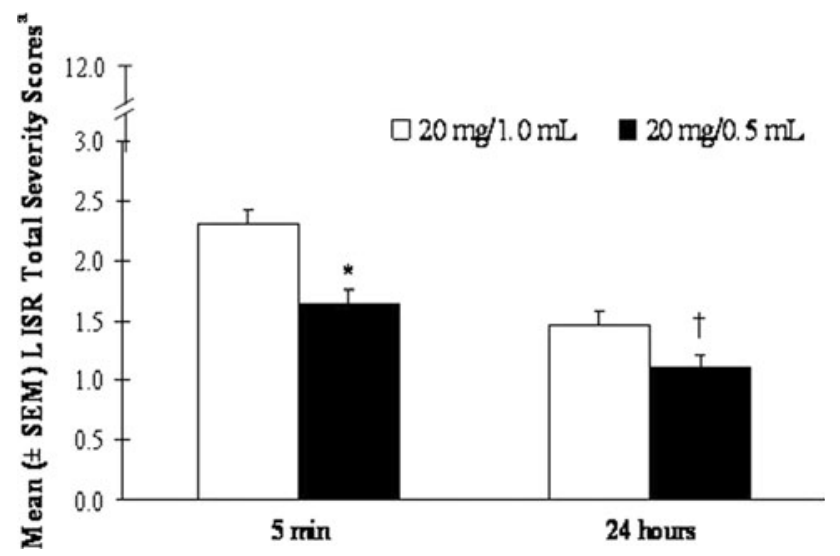

Fig. 4 Mean $( \pm$ SEM) LISR total severity score $5 \mathrm{~min}$ and $24 \mathrm{~h}$ after injection of $20 \mathrm{mg} / 0.5 \mathrm{~mL} \mathrm{GA}$ or $20 \mathrm{mg} / 1.0 \mathrm{~mL}$ GA. ${ }^{\mathrm{a}}$ As indicated on the $Y$ axis, LISR total severity scores could range from 0 to 12 per patient depending on the severity ( 0 "none" to 3 "severe") for each of the four LISRs experienced: redness, itching, swelling and lump. $* p<0.0001 ; 20 \mathrm{mg} / 0.5 \mathrm{~mL}$ LS mean 125.3, 95\% CI 112.0-138.6; and $20 \mathrm{mg} / 1.0 \mathrm{~mL}$ LS mean 162.2, 95\% CI 148.9-175.6. ${ }^{\dagger} p<0.0001 ; 20 \mathrm{mg} / 0.5 \mathrm{~mL}$ LS mean $132.0,95 \%$ CI 118.5-145.6; and $20 \mathrm{mg} / 1.0 \mathrm{~mL}$ LS mean $155.8,95 \%$ CI 142.2-169.3

\section{Severity of LISRs}

The mean LISR total severity score within 5 min after administration was rated 1.64 for $20 \mathrm{mg} / 0.5 \mathrm{~mL} \mathrm{GA}$ and rated 2.30 for $20 \mathrm{mg} / 1.0 \mathrm{~mL}$ GA (Fig. 4, maximum score could be 12). The $20 \mathrm{mg} / 0.5 \mathrm{~mL}$ GA preparation was associated with a significantly lower mean LISR symptom severity score than the $20 \mathrm{mg} / 1.0 \mathrm{~mL}$ GA within $5 \mathrm{~min}$ post-injection ( $p<0.0001$; mean ranked scores were 125.3, 95\% CI 112.0-138.6 and 162.2, 95\% CI 148.9-175.6, respectively, with no treatment period and formulation sequence effects).

Within the 24-h time point, treatment with $20 \mathrm{mg} /$ $0.5 \mathrm{~mL}$ GA was associated with a mean LISR severity score of 1.10, whereas treatment with $20 \mathrm{mg} / 1.0 \mathrm{~mL}$ GA was associated with a mean LISR severity score of 1.47 (Fig. 4). As indicated by the LS mean for treatment effect, the $20 \mathrm{mg} / 0.5 \mathrm{~mL}$ GA preparation produced a significantly less severe mean LISR score within $24 \mathrm{~h}$ post-injection than the $20 \mathrm{mg} / 1.0 \mathrm{~mL} \mathrm{GA}$ preparation $(p<0.0001$; mean ranked scores were $132.0,95 \%$ CI $118.5-145.6$ and 155.8 , 95\% CI 142.2-169.3, respectively, with no treatment period and formulation sequence effects).

\section{No symptoms}

Most patients reported some LISR symptoms within 5 min following injection of either formulation. It is interesting to note, though, that the percentage of patients reporting no symptoms within $5 \mathrm{~min}$ of the $20 \mathrm{mg} / 0.5 \mathrm{~mL} \mathrm{GA}$ injection was twice the percentage of patients reporting no symptoms within $5 \mathrm{~min}$ of the $20 \mathrm{mg} / 1.0 \mathrm{~mL}$ GA (Fig. 5). Likewise, within $24 \mathrm{~h}$ post-injections, the majority of patients reported LISR symptoms; however, more patients reported no symptoms after injecting $20 \mathrm{mg} / 0.5 \mathrm{~mL} \mathrm{GA}$ than after injecting $20 \mathrm{mg} / 1.0 \mathrm{~mL}$ GA (Fig. 5).
Fig. 5 Percentage of patients reporting no LISR symptoms $5 \mathrm{~min}$ and $24 \mathrm{~h}$ after injection of $20 \mathrm{mg} / 0.5 \mathrm{~mL} \mathrm{GA}$ or $20 \mathrm{mg} /$ $1.0 \mathrm{~mL}$ GA on days $0-3$, days $4-6$, days 7-9, and days $>9$

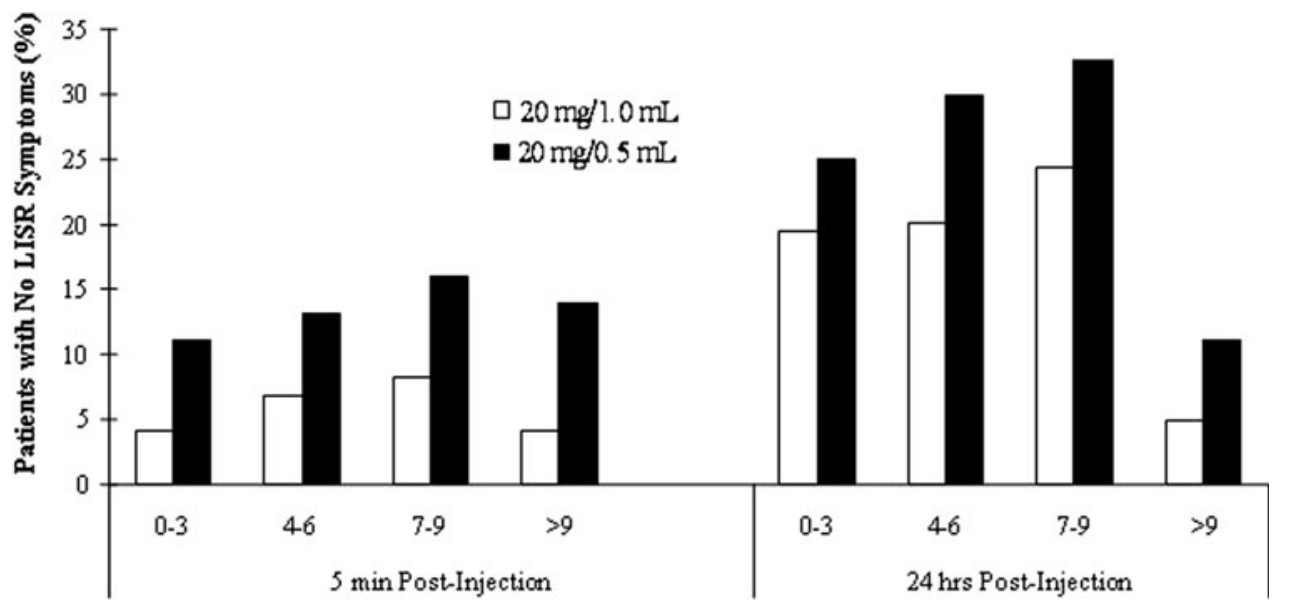

Day Intervals (days) 


\section{Adverse events}

Both formulations of GA were well tolerated. During the study there were no deaths, serious adverse events (SAEs), or AEs that lead to discontinuation. No significant changes in the laboratory parameters, vital signs, physical examinations, or neurological examinations were noted compared to baseline assessments or between formulations. The percentage of patients reporting AEs was low $(<20 \%)$ for both treatments. During the entire period of the study, 27 AEs were reported for $18(12.5 \%)$ patients treated with $20 \mathrm{mg} /$ $1.0 \mathrm{~mL}$ GA, and 38 AEs were reported for $26(18.1 \%)$ patients treated with $20 \mathrm{mg} / 0.5 \mathrm{~mL}$ GA. The most frequently reported AEs after administration of $20 \mathrm{mg} / 0.5 \mathrm{~mL}$ GA were urinary tract infection $(2.8 \%)$, viral upper respiratory tract infection $(1.4 \%)$, arthralgia $(1.4 \%)$, and headache (1.4\%). The most frequently reported AEs after administration of $20 \mathrm{mg} / 1.0 \mathrm{~mL} \mathrm{GA}$ were contusion (1.4\%), muscular weakness (1.4\%), and ataxia (1.4\%). Two severe AEs were reported during the study: severe biliary dyskinesia during the run-in period and severe hypertonia after administration of $20 \mathrm{mg} / 1.0 \mathrm{~mL} \mathrm{GA}$. Both events were not related to the study treatment and resolved within 2 days. All other AEs were either mild or moderate in intensity.

Treatment-related AEs were reported for two patients during the run-in period $(20 \mathrm{mg} / 1.0 \mathrm{~mL} \mathrm{GA})$ : one patient had biliary dyskinesia and one patient had presyncope. Treatment-related AEs were reported for three patients (2.1\%) during the $20 \mathrm{mg} / 1.0 \mathrm{~mL} \mathrm{GA}$ treatment period: increased hepatic enzyme $(n=1)$, anxiety and panic attack $(n=1$ patient), and headache $(n=1)$. Similarly, treatment-related AEs were reported for four patients $(2.8 \%)$ during the $20 \mathrm{mg} / 0.5 \mathrm{~mL}$ GA treatment period: headache and injection site nodule $(n=1$ patient), panic attack ( $n=1$ patient), dyspnea ( $n=1$ patient), and constipation ( $n=1$ patient). None of the treatment-related AEs were severe in intensity.

Two AEs related to the injection-site were reported during the study. One patient reported injection site necrosis on day 2 of the run-in period. The event was mild in intensity and not considered to be related to the study treatment. Another patient reported injection site nodule on day 1 of Period 1 of the $20 \mathrm{mg} / 0.5 \mathrm{~mL}$ GA treatment. The event was mild in intensity, considered to be related to the study treatment, and spontaneously resolved after 10 days.

\section{Discussion}

Overall, the results demonstrate a significant improvement in injection pain and LISRs (swelling, redness, itching, and lump) with the novel formulation compared with the marketed formulation. The mean pain scores were low for both formulations; however, the mean immediate VAS total pain score was significantly lower after administration of $20 \mathrm{mg} / 0.5 \mathrm{~mL} \mathrm{GA}$ injection compared with the $20 \mathrm{mg} /$ $1.0 \mathrm{~mL}$ GA injection. The lower immediate VAS pain score associated with the novel formulation was consistent over all 14 days of the study, indicating that the improvement in injection pain did not diminish over time. The reduced VAS pain score associated with the novel formulation was also evident 5 min post-injection.

The initial onset of LISRs experienced by patients can lead them to discontinue treatment or miss injections. With the realization that LISRs may lead to non-adherence, researchers have been investigating ways to limit LISRs [13, 14]. Use of warm compresses and rotating the injection site seem to have a moderate effect [13]. As evidenced by the present study, reducing the volume may also provide a moderate benefit. The incidence and severity of LISRs within $5 \mathrm{~min}$ and $24 \mathrm{~h}$ post-injection were significantly less for the novel formulation than the marketed formulation. Moreover, even though most patients reported some LISRs following injection of either formulation, a greater percentage of patients treated with the reduced volume solution reported no symptoms within $5 \mathrm{~min}$ and $24 \mathrm{~h}$ after injection. A longer study duration would be needed to determine whether the improvement in injection pain and LISRs associated with the novel formulation improves quality of life, incidence of lipoatrophy, and long-term drug adherence.

A limitation of the study is that it was not blinded. Although blinding of the administered volume of the dose represents a superior experimental design, it was not possible to implement in the present trial for several reasons. First, the patients would have been required to be seen at the clinic every day, for a total of 35 days, to receive their injection. It would have been logistically very difficult for the large number of patients required for this trial, and place too great a burden on these patients to undertake daily visits. Second, to blind the volume of the formulation in the syringe, it would not have been sufficient to cover the syringe with opaque tape, or use a syringe with opaque glass, as the differences in the length of the syringe plunger, related to differences in the volume, would have been noticed by the patients. A new syringe with a redesigned plunger was not available for this study. However, it is important to note that, although the patients were able to detect a difference in the volume of the formulation, the trial investigators took care not to present one formulation as "better" or "superior" than the other formulation. In addition, patient diaries were collected after each period of the trial so that patients did not have the results of the previous entries for comparison purposes.

Both formulations had a good tolerability and safety profile. The percentage of subjects reporting AEs was low $(<20 \%)$ for both treatments. All AEs were reported 
previously and there were no unexpected laboratory values. The novel formulation has the potential to improve patient adherence by producing less pain, and fewer and less severe LISRs. The $20 \mathrm{mg} / 0.5 \mathrm{~mL}$ formulation is a more tolerable option for patients using subcutaneous injections of GA. Since injection site reactions, including pain, are the most frequently reported AEs in subjects receiving daily injections of GA for RRMS, the $20 \mathrm{mg} / 0.5 \mathrm{~mL}$ formulation may offer clinical benefits for patients.

Acknowledgments The authors thank Stephen Glenski, PharmD, of the Medical Affairs division of Teva Neuroscience (Kansas City, MO) for assistance with the design, conduction, and analysis of the study. The statistical analyses were conducted by i3 Research (a division of Ingenix Research Pharmaceutical Services, Inc. Basking Ridge, NJ). The authors thank Heather S. Oliff, PhD (Science Consulting Group LLC, North Tustin, CA) and Pippa Loupe, PhD (Medical Affairs, Teva Neuroscience, Kansas City, MO) for assistance with this article. The study was funded by Teva Neuroscience, Kansas City, MO.

Conflict of interest Gregory Anderson has received honoraria and/ or research funding from the following companies: Teva Neuroscience, Glaxo Smith Kline, Biogen Idec, Johnson and Johnson, Eli Lilly, Genzyme, Opexa, Merck, Supernus, Boehringer Ingelheim, Janssen, and Elan. Ronald Murray has received honoraria and/or research funding from the following companies: Teva Neuroscience, Pfizer, Bayer Health Care, and Biogen Idec. David Meyer has received honoraria and/or research funding from the following companies: Teva Neuroscience, Biogen Idec, Bayer, EMD Serono, Forest, Novartis, Pfizer, and Eli Lilly. Craig Herrman has received honoraria from Biogen Idec and research funding from Teva Neuroscience. Christopher Sheppard has received honoraria and/or research funding from Teva Neuroscience, Biogen Idec, and EMD Serono Pharmaceuticals. Edward Fox has received a honoraria and/or research funding from the following companies: Bayer, Biogen-Idec, EMD Serono, Genzyme, Opexa Therapeutics, Pfizer, Teva Neuroscience, Eli Lilly, Ono, and Sanofi-Aventis. Jill Conner is an employee of Teva Neuroscience (Kansas City, MO), a division of Teva Pharmaceuticals, Inc, Petah Tiqva, Israel. Julie Malthena is an employee of Teva Neuroscience (Kansas City, MO), a division of Teva Pharmaceuticals, Inc, Petah Tiqva, Israel. Phil Buck is an employee of Teva Neuroscience (Kansas City, MO), a division of Teva Pharmaceuticals, Inc, Petah Tiqva, Israel.

Open Access This article is distributed under the terms of the Creative Commons Attribution Noncommercial License which permits any noncommercial use, distribution, and reproduction in any medium, provided the original author(s) and source are credited.
2. Comi G, Filippi M, Wolinsky JS (2001) European/Canadian multicenter, double-blind, randomized, placebo-controlled study of the effects of glatiramer acetate on magnetic resonance imaging - measured disease activity and burden in patients with relapsing multiple sclerosis. European/Canadian Glatiramer Acetate Study Group. Ann Neurol 49:290-297

3. Ford CC, Johnson KP, Lisak RP, Panitch HS, Shifronis G, Wolinsky JS (2006) A prospective open-label study of glatiramer acetate: over a decade of continuous use in multiple sclerosis patients. Mult Scler 12:309-320

4. Johnson KP, Brooks BR, Cohen JA, Ford CC, Goldstein J, Lisak $\mathrm{RP}$ et al (1995) Copolymer 1 reduces relapse rate and improves disability in relapsing-remitting multiple sclerosis: results of a phase III multicenter, double-blind placebo-controlled trial. The Copolymer 1 Multiple Sclerosis Study Group. Neurology 45:1268-1276

5. Johnson KP, Brooks BR, Cohen JA, Ford CC, Goldstein J, Lisak $\mathrm{RP}$ et al (1998) Extended use of glatiramer acetate (Copaxone) is well tolerated and maintains its clinical effect on multiple sclerosis relapse rate and degree of disability. Copolymer 1 Multiple Sclerosis Study Group. Neurology 50:701-708

6. Ford C, Goodman AD, Johnson K, Kachuck N, Lindsey JW, Lisak R et al (2010) Continuous long-term immunomodulatory therapy in relapsing multiple sclerosis: results from the 15-year analysis of the US prospective open-label study of glatiramer acetate. Mult Scler 16:342-350

7. Osterberg L, Blaschke T (2005) Adherence to medication. N Engl J Med 353:487-497

8. Lugaresi A (2009) Addressing the need for increased adherence to multiple sclerosis therapy: can delivery technology enhance patient motivation? Expert Opin Drug Deliv 6:995-1002

9. Stuart WH (2004) Clinical management of multiple sclerosis: the treatment paradigm and issues of patient management. J Manag Care Pharm 10:S19-S25

10. Treadaway K, Cutter G, Salter A, Lynch S, Simsarian J, Corboy J et al (2009) Factors that influence adherence with disease-modifying therapy in MS. J Neurol 256:568-576

11. Turner AP, Williams RM, Sloan AP, Haselkorn JK (2009) Injection anxiety remains a long-term barrier to medication adherence in multiple sclerosis. Rehabil Psychol 54:116-121

12. Jorgensen JT, Rømsing J, Rasmussen M, Møller-Sonnergaard J, Vang L, Musaeus L (1996) Pain assessment of subcutaneous injections. Ann Pharmacother 30:729-732

13. Jolly H, Simpson K, Bishop B, Hunter H, Newell C, Denney D et al (2008) Impact of warm compresses on local injection-site reactions with self-administered glatiramer acetate. J Neurosci Nurs 40:232-239

14. Pardo G, Boutwell C, Conner J, Denney D, Oleen-Burkey M (2010) Effect of oral antihistamine on local injection site reactions with self-administered glatiramer acetate. J Neurosci Nurs 42:40-46

\section{References}

1. (2009) Copaxone (Glatiramer acetate injection) prescribing information. Teva Pharmaceuticals USA, Inc, North Wales 